\title{
Comparison of the tube thoracostomy techniques on treatment in COVID-19 patients with pneumothorax
}

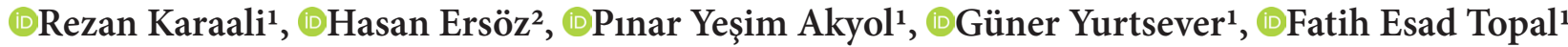 \\ ${ }^{1}$ İzmir Katip Celebi University, Atatürk Training and Research Hospital, Department of Emergency Medicine, İzmir, Turkey \\ ${ }^{2}$ İzmir Katip Celebi University, Atatürk Training and Research Hospital, Department of Thoracic Surgery, İzmir, Turkey
}

Cite this article as: Karaali R, Ersöz H, Akyol PY, Yurtsever G, Topal FE. Comparison of the tube thoracostomy techniques on treatment in COVID-19 patients with pneumothorax. J Health Sci Med 2022; 5(1): 306-312.

\begin{abstract}
Aim: Tube thoracostomy is an interventional procedure in which there is a high risk for the spread of COVID-19. In this study, we compare the tube thoracostomy procedures performed early on in the pandemic and those performed later after steps were taken in accordance with the new recommendations.

Material and Method: It is a retrospective and single-center study. COVID-19 patients with spontaneous pneumothorax with indications for tube thoracostomy presented to our emergency department between March 10, 2020, and March 31, 2021. Based on the applied tube techniques, two groups were defined; group 1, patients who underwent classical tube thoracostomy, group 2, patients who underwent tube thoracostomy with the recommended preventive measures for COVID-19. The collected data were compared between the two groups.

Results: 106 patients met the study criteria and were included in the study. The difference in the length of the tube duration time between the old or new technique was statistically significant $(\mathrm{p}<0.05)$, no difference was identified in the duration of stay, intensive care unit admission, or mortality compared with the two techniques.

Conclusions: In this study, the new measures recommended for tube thoracostomy were found to be effective for the treatment of patients.
\end{abstract}

Keywords: COVID-19, emergency, pneumothorax, tube thoracostomy

\section{INTRODUCTION}

Pneumothorax (PNX) refers to the presence of air between the leaves of the pleura, and can occur as spontaneous, traumatic or iatrogenic. In the case of air $>15 \%$ in the hemithorax, the treatment is tube thoracostomy (TT) and underwater seal drainage (UWSD) (1). Conventional UWSD bottles have an outlet that can be connected to negative pressure systems, but if it is not connected to the underwater seal drainage system, the air draining from the pleural cavity into the bottle escapes into the room air via this outlet (2-4).

Coronavirus disease-19 (COVID-19), which is still affecting the entire world, involves mainly the respiratory tract and lungs, and is transmitted via droplets. Case reports and studies published since the declaration of the pandemic have shown that PNX may be a symptom of COVID-19 pneumonia, or may occur during the course and treatment of COVID-19 (5-7). As specified in the American Association for Thoracic Surgery (AATS) and
British Thoracic Society (BTS) guidelines, all patients requiring hospitalization should be tested for the presence of COVID-19 $(3,8)$. It has been recommended that level 3 personnel protective equipment (PPE) be used for patients requiring interventional procedures, and that COVID-19 be ruled out by Real-Time Reverse Transcription Polymerase Chain Reaction (RT-PCR) tests, computed tomography (CT) scans and blood tests. For patients with indications of TT, it is recommended that household bleach (5.25-6.15\% sodium hypochlorite) be put into the UWSD bottle at a ratio of 1:50, and a filter be installed on the outlet, as a means of preventing the entry of any viral particles in the air drained from the pleural cavity from mixing with the room air (2-4). As the outbreak has progressed, changes have been made to our approach to PNX patients following the development of treatment guidelines, and the introduction of preventive measures and recommendations. 
In this study we compare the TT procedures performed early on in the pandemic and those performed later after steps were taken in accordance with the new recommendations. Our aim in this study is to compare efficiency between these two types of practices on the patient prognosis and mortality.

\section{MATERIAL AND METHOD}

\section{Ethical Approval}

The study was initiated upon the granting of approval by the Turkish Ministry of Health, dated January 02, 2021 and numbered T21-31-12, and by the İzmir Katip Çelebi University Ethics Committee dated January 21, 2021 and numbered 003 . All procedures were carried out in accordance with the ethical rules and the principles of the Declaration of Helsinki. All persons included in the study signed the an Informed Consent Form.

\section{Study Population}

Included in this, retrospective and single-center study were patients with spontaneous PNX with indications for TT who presented to our emergency department between March 10, 2020 and March 31, 2021.

Since the onset of the pandemic, the initial assessment and intervention of PNX patients with indications of TT who present to the emergency department of our hospital have been carried out with the assumed presence of COVID-19. Patients who are to receive TT are taken to a confined intervention area and the intervention is performed by an emergency medicine specialist, an emergency medicine assistant and a member of the allied healthcare personnel, all of whom wear level 3 PPE. As of June 2020, in line with the published recommendations, sodium hypochlorite has been placed in the UWSD bottles and a High-Efficiency Particulate Arrestance (HEPA, Meditera-Altech ${ }^{\circledR}$ ) filter has been fixed to the outlet (Figure 1), in addition to the PPE measures for patients with indications for TT $(3,8,9)$.

Since the COVID-19 outbreak, every patient with indications for hospitalization has been evaluated for COVID-19, with an RT-PCR test (Bio-speedy COVID-19 RT-qPCR test) performed for every patient, as recommended by the Diagnosis and Treatment Protocol for Novel Coronavirus Pneumonia (10). The patients are then transferred to the isolation ward or the intensive care unit, depending on the COVID-19 test result. For patients with negative test results, a control PCR test is performed at their place of residence (10). Included in the study were patients over the age of 18 years who were not pregnant, nontraumatic, who recorded at least one positive test result and who had sufficient data in their records.

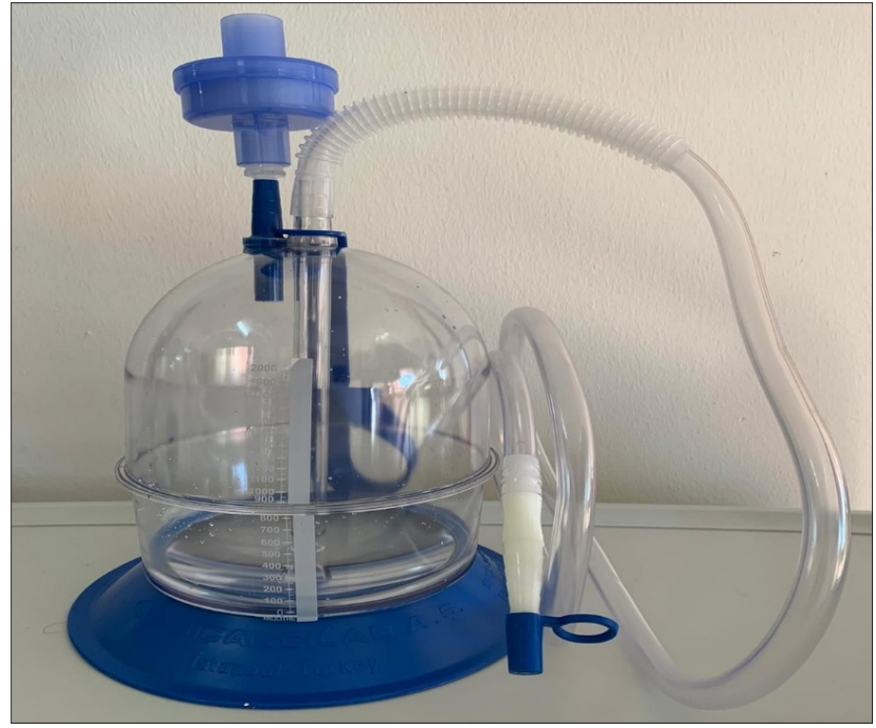

Figure 1. Household bleach (1:50) has been placed in the UWSD bottles and a High-Efficiency Particulate Arrestance (HEPA, Meditera-Altech $^{\circ}$ ) filter has been fixed to the outlet

Two groups were defined in the study, based on the applied tube thoracostomy technique:

- Group 1 includes patients who presented prior to June 1, 2020 and who received TT due to spontaneous PNX. In this group, a filter was not installed on the outlet of the UWSD bottle and no sodium hypochlorite was put into the bottle in this group.

- Group 2 includes patients who presented in or after June 1, 2020 and who received TT due to spontaneous PNX. Unlike in Group 1, in this group, a HEPA filter was installed on the outlet of the UWSD bottle, and sodium hypochlorite was placed into the bottle during TT treatments in this group of patients.

Tube thoracostomy of the patients were removed when all three criteria were met in both groups. Those three criteria were complete cessation of the air leak in the pleura, full expansion of the lungs on the chest $\mathrm{x}$-ray of the patients, daily amount of pleural fluid drained equal to or less than $100 \mathrm{ml}$ (8). Tube thoracostomies were removed when all three criteria were matched at the same time on a day.

\section{Study Protocol}

The age and gender of the patients were recorded, along with smoking status, and comorbidities were classified as pulmonary and non-pulmonary, along with hospitalization status (intensive care unit/ward), length of stay, tube duration time, body mass index (BMI) and laboratory parameters. Concerning the COVID-19 findings, thoracic CT scans were interpreted based on the Radiological Society of North America (RSNA) criteria (11). The patients were divided into two groups, as denoted above, and the collected data between the two groups were compared. We recorded 30-day mortality in patients, compared between the two groups, and examined the factors affecting mortality. 


\section{Statistical Method}

The study data were assessed using IBM SPSS Statistics Version 20. The use of parametric or nonparametric tests was decided by analyzing the normality of the quantitative data using the One-Sample Kolmogorov-Smirnov test. Frequency and percentage distribution were calculated for descriptive statistics and mean, standard deviation, median, minimum and maximum values for continuous variables. The Pearson's Chi-Square and Fisher's Exact tests were used to compare categorical variables between groups. Categorical data were expressed as $n$ (number) and percentages (\%). The significance of the values was examined by using the Independent $\mathrm{T}$ test and the Mann Whitney $U$ tests in the comparison of independent groups.The effect of laboratory values in determining the mortality of the patients was examined by Receiver Operating Characteristic (ROC) analysis and the cut-off values of the variables with statistical differences were calculated. Binary logistic regression model was used to analysis factors affecting mortality.

Statistical significance level was set at $\mathrm{p}<0.05$.

\section{RESULTS}

During the study period, 191 patients presented to our emergency department and were diagnosed with spontaneous PNX, among which, 106 met the study criteria and were included in the study. In our patient series, $81.10 \%$ were male, and the mean age was $44.46 \pm 21.57$ and $57.40 \pm 21.73 /$ years for the male and female patients, respectively. The demographic characteristics of the patients and distribution of variables are presented in Table 1.

TT was performed using the traditional method in $36.80 \%$ of the patients. A comparison of the tube duration time of the patients group 1 and group 2 revealed a mean duration of 4.7 days in the 39 patients group 1, and 2.6 days in the 67 patients group 2 . The difference in the tube duration time between the group 1 and group 2 patients was statistically significant $(p<0.05)$, although no difference was identified in the duration of stay, ICU/ward admission or mortality associated with the two groups (Table 1).

An evaluation of the mortality data revealed that $55.56 \%$ of the patients who died were male, the mean age was $66.11 \pm 21.00$ /years, $94.40 \%$ were staying in the intensive care unit, the mean length of hospital stay was $17.88 \pm 20.45 /$ days and $72.2 \%$ had comorbidities. A statistically significant difference was noted in all the above parameters between the non-surviving and surviving patients (Table 2).

Another parameter that affected mortality was the laboratory values of the patients (Table 3), among which, C-Reactive protein (CRP), International Normalized

\begin{tabular}{|c|c|c|c|c|}
\hline \multirow[t]{2}{*}{ Variables } & $\begin{array}{c}\text { Total } \\
\text { patients }\end{array}$ & $\begin{array}{c}\text { Tradiditional } \\
\text { TT } \\
\text { procedure }\end{array}$ & $\begin{array}{c}\text { Preventive } \\
\text { TT } \\
\text { procedure }\end{array}$ & \multirow{2}{*}{$\mathbf{p}$} \\
\hline & Mean \pm SD & Mean \pm SD & Mean \pm SD & \\
\hline \multicolumn{4}{|l|}{ Age/year } & \multirow[t]{3}{*}{0.386} \\
\hline Male & $44.65 \pm 20.69$ & $42.00 \pm 17.20$ & $45.72+22.17$ & \\
\hline Female & $57.40 \pm 21.60$ & $51.8 \pm 15.70$ & $63.00 \pm 26.91$ & \\
\hline $\begin{array}{l}\text { Tube duration } \\
\text { time (days) }\end{array}$ & $3.40 \pm 2.16$ & $4.76 \pm 2.39$ & $2.67 \pm 1.53$ & 0 \\
\hline BMI (kg/m2) & $23.43 \pm 3.35$ & $23.64 \pm 2.89$ & $23.29 \pm 3.62$ & 0.609 \\
\hline $\begin{array}{l}\text { Hospitalization } \\
\text { duration (days) }\end{array}$ & $10.12 \pm 11.35$ & $11.89 \pm 13.13$ & $9.08 \pm 10.12$ & 0.221 \\
\hline Variables & n (\%) & n (\%) & n (\%) & $\mathbf{p}$ \\
\hline $\begin{array}{l}\text { Number of } \\
\text { patients }\end{array}$ & $106(100)$ & $39(37)$ & $67(63)$ & \\
\hline \multicolumn{5}{|l|}{ Gender } \\
\hline Male & $86(81.13)$ & $29(74.36)$ & $57(85.07)$ & 0.174 \\
\hline Female & $20(18.87)$ & $10(25.64)$ & $10(14.93)$ & \\
\hline Smoking & & & & 0.048 \\
\hline Yes & $63(59.43)$ & $28(71.79)$ & $35(52.24)$ & \\
\hline No & $43(40.57)$ & $11(28.21)$ & $32(47.76)$ & \\
\hline None & $69(65.09)$ & $26(66.67)$ & $43(64.18)$ & 0.643 \\
\hline \multicolumn{5}{|l|}{ Comorbidity } \\
\hline $\begin{array}{l}\text { Pulmonary } \\
\text { disease }\end{array}$ & $19(17.92)$ & $8(20.51)$ & $11(16.42)$ & \\
\hline $\begin{array}{l}\text { Nonpulmonary } \\
\text { disease }\end{array}$ & $18(16.98)$ & $5(12.82)$ & $13(19.4)$ & \\
\hline \multicolumn{5}{|c|}{ Hospitalization Area } \\
\hline ICU & $27(25.47)$ & $10(25.64)$ & $17(25.37)$ & 0.976 \\
\hline Ward & $79(74.53)$ & $29(74.36)$ & $50(74.63)$ & \\
\hline \multicolumn{5}{|l|}{ CT findings } \\
\hline $1^{\text {st }}$ group & $51(48.11)$ & $19(48.72)$ & 32 (47.76) & 0.924 \\
\hline $2^{\text {nd }}$ group & $55(51.89)$ & $20(51.28)$ & $35(52.24)$ & \\
\hline \multicolumn{5}{|l|}{ Mortality } \\
\hline Nonsurvivor & $18(16.98)$ & $8(20.51)$ & $10(14.93)$ & 0.46 \\
\hline Survivor & $88(83.02)$ & $31(79.49)$ & 57 (85.07) & \\
\hline $\begin{array}{l}\text { TT: Tube Thoracostomy } \\
\text { computedtomography, } \\
\text { 2: RadiologicalSociety o }\end{array}$ & $\begin{array}{l}\text { ICU: Intensiveca } \\
\text { Group 1: Radiolog } \\
\text { of North America }\end{array}$ & $\begin{array}{l}\text { areunit, BMI: body } \\
\text { gicalSociety of Nort } \\
\text { Type 3-4 }\end{array}$ & $\begin{array}{l}\text { massindex, CT: } \\
\text { th AmericaType } 1\end{array}$ & -2, Group \\
\hline
\end{tabular}

Ratio (INR) and D-dimer were associated with mortality. CRP had a sensitivity of $55.6 \%$ and a specificity of $27.3 \%$ for a cut-off value of 38.12 (AUC: 0.694 ; $95 \%$ CI $0.558-$ 0830); INR had a sensitivity of $61.1 \%$ and a specificity of $23.9 \%$ for a cut-off value of 1.15 (AUC: $0.729 ; 95 \%$ CI $0.579-0.879$ ); and D-Dimer had a sensitivity of $72.2 \%$ and a specificity of $29.5 \%$ for a cut-off value of 827.5 (AUC: 0.723 ; 95\% CI 0.599-0.848).

In order to determine the variables that may affect the mortality of the patients, the data obtained in the study were analysed with the "Binary Logistic Regression Model". Mortality was determined as the response variable. According to the analysis results, variables with $a(p)$ value below $0.25(p<0.25)$ are included in the model. However, there is no fundamental variable that can be included in the model and is at a level that will directly affect mortality as a result of the analysis (Table 4). 


\begin{tabular}{|c|c|c|c|}
\hline Variables & Nonsurvivors n (\%) & Survivors n (\%) & $\mathbf{p}$ \\
\hline Gender & & & 0.006 \\
\hline Male & $10(55.56)$ & $76(86.36)$ & \\
\hline Female & $8(44.44)$ & $12(13.64$ & \\
\hline Smoking & & & 0.225 \\
\hline Yes & $13(72.2)$ & $50(59.4)$ & \\
\hline No & $5(27.8)$ & $38(40.6)$ & \\
\hline Comorbidity & & & 0.001 \\
\hline None & $5(27.8)$ & $64(72.7)$ & \\
\hline $\begin{array}{l}\text { Pulmonary } \\
\text { disease }\end{array}$ & $6(33.3)$ & $13(14.8)$ & \\
\hline $\begin{array}{l}\text { Nonpulmonary } \\
\text { disease }\end{array}$ & $7(38.9)$ & $11(12.5)$ & \\
\hline CT Findings & & & 0.226 \\
\hline $1^{\text {st }}$ group & $11(61.11)$ & $40(45.45)$ & \\
\hline $2^{\text {nd }}$ group & $7(38.89)$ & $48(54.55)$ & \\
\hline TT procedure & & & 0.46 \\
\hline $\begin{array}{l}\text { Traditional } \\
\text { procedure }\end{array}$ & $8(44.44)$ & $31(35.26-3)$ & \\
\hline $\begin{array}{l}\text { Preventive } \\
\text { procedure }\end{array}$ & $10(55.56)$ & $57(64.77)$ & \\
\hline Variables & $\begin{array}{l}\text { Mean } \pm \text { SD } \\
(\text { Min-Max) }\end{array}$ & $\begin{array}{c}\text { Mean } \pm \text { SD } \\
(\text { Min-Max) }\end{array}$ & $\mathbf{p}$ \\
\hline Age (Year) & & & 0.057 \\
\hline Male & $\begin{array}{c}60.20 \pm 24.17 \\
(18-96)\end{array}$ & $\begin{array}{c}43.39 \pm 19.59 \\
(18-96)\end{array}$ & \\
\hline Female & $\begin{array}{l}73.50 \pm 14.42 \\
(42-89)\end{array}$ & $\begin{array}{c}46.67 \pm 20.12 \\
(23-89)\end{array}$ & \\
\hline Total & $\begin{array}{l}66.11 \pm 21.00 \\
(18-96)\end{array}$ & $\begin{array}{l}42.98 \pm 19.60 \\
(18-96)\end{array}$ & \\
\hline $\begin{array}{l}\text { Tube duration } \\
\text { time days }\end{array}$ & $\begin{array}{c}4.5 \pm 2.21 \\
(1-14)\end{array}$ & $\begin{array}{c}3.18 \pm 2.16 \\
(1-14)\end{array}$ & 0.18 \\
\hline $\begin{array}{l}\text { Hospitalization } \\
\text { duration days }\end{array}$ & $\begin{array}{l}17.88 \pm 20.45 \\
(2-68)\end{array}$ & $\begin{array}{c}8.56 \pm 7.69 \\
(2-68)\end{array}$ & 0.01 \\
\hline BMI kg /m2 & $\begin{array}{r}23.61 \pm 3.88 \\
(15.4-31.10)\end{array}$ & $\begin{array}{l}23.39 \pm 13.26 \\
(15.4-32.70)\end{array}$ & 0.802 \\
\hline
\end{tabular}

\section{DISCUSSION}

Pandemics require a long-term fight, and healthcare workers are on the front line of this fight, being the occupational group at the highest risk of infection. Special precautions should be taken in applications such as tube thoracostomy that result in air leak in air-borne infections. Therefore, some precautions have been recommended for the tube thoracostomy applications in patients who simultaneously have SARS-CoV-2 infection and PNX. Ceylan et al. (9) and Gedik et al. (12) used a two-bottle technique. In this technique, trap (collection) and underwater seal bottles were used. A high-efficiency particulate air (HEPA) viral filter was placed on the tip of the underwater seal bottle filled only with $200 \mathrm{cc}(80 \%)$ alcohol instead of water alone. Pieracci et al. (3), and Irons et al. (13), suggested connection of the exit line to the suction in addition to using a HEPA filter. A transmission prevention protocol was used in this present study as was recommended by

\begin{tabular}{|c|c|c|c|c|}
\hline \multirow{2}{*}{$\begin{array}{l}\text { Laboratory } \\
\text { parameteres }\end{array}$} & Total patients & Nonsurvivors & Survivors & \multirow[b]{2}{*}{$\mathbf{p}$} \\
\hline & $\begin{array}{l}\text { Mean } \pm \text { SD } \\
\text { Min-max }\end{array}$ & $\begin{array}{l}\text { Mean } \pm \text { SD } \\
\text { Min-max }\end{array}$ & $\begin{array}{l}\text { Mean } \pm \text { SD } \\
\text { Min-max }\end{array}$ & \\
\hline $\mathrm{WBC} / 10^{9} / \mathrm{L}$ & $\begin{array}{c}13.63 \pm 5.88 \\
4.11-32.95\end{array}$ & $\begin{array}{l}14.39 \pm 5.78 \\
4.41-26.08\end{array}$ & $\begin{array}{l}13.48 \pm 5.93 \\
4.11-32.95\end{array}$ & 0.414 \\
\hline HCT/\% & $\begin{array}{c}38.65 \pm 5.22 \\
15.92-48\end{array}$ & $\begin{array}{l}34.15 \pm 7.37 \\
15.92-45.4\end{array}$ & $\begin{array}{c}39.57 \pm 4.16 \\
27.9-48\end{array}$ & 0.001 \\
\hline PLT/ $\mu \mathrm{lt}$ & $\begin{array}{c}280.15 \pm 124.06 \\
90-883\end{array}$ & $\begin{array}{c}275.44 \pm 191.51 \\
90-883\end{array}$ & $\begin{array}{c}281.11 \pm 106.79 \\
114-564\end{array}$ & 0.224 \\
\hline CRP mg/L & $\begin{array}{c}52.21 \pm 81.06 \\
0-416.21\end{array}$ & $\begin{array}{c}106.75 \pm 121.39 \\
0.2-416.21\end{array}$ & $\begin{array}{c}41.05 \pm 65.65 \\
0-258.42\end{array}$ & 0.01 \\
\hline INR & $\begin{array}{l}1.21 \pm 0.58 \\
0.92-6.62\end{array}$ & $\begin{array}{l}1.65 \pm 1.31 \\
0.98-6.62\end{array}$ & $\begin{array}{c}1.12 \pm 0.16 \\
0.92-1.9\end{array}$ & 0.002 \\
\hline $\begin{array}{l}\text { D-DIMER } \\
\mathrm{mg} / \mathrm{L}\end{array}$ & $\begin{array}{c}941.89 \pm 1000.16 \\
112-4526\end{array}$ & $\begin{array}{c}1513.39 \pm 1104.95 \\
230-3300\end{array}$ & $\begin{array}{c}825 \pm 941.98 \\
112-4526\end{array}$ & 0.003 \\
\hline
\end{tabular}

Table 4. Binary Logistic Regression anlaysis of effect of variables on mortality.

\begin{tabular}{|c|c|c|c|c|c|c|}
\hline Variables in theEquation & B & S.E. & Wald & df & Sig. & $\operatorname{Exp}(B)$ \\
\hline \multicolumn{7}{|l|}{ Step 1a } \\
\hline gender (1) & -20.342 & 3647.997 & .000 & 1 & .996 & .000 \\
\hline Tube Technic (1) & 55.706 & 4501.210 & .000 & 1 & .990 & 1558480290115094300000000.000 \\
\hline ICU, ward (1) & 210.869 & 10331.371 & .000 & 1 & .984 & $3.795 \mathrm{E}+091$ \\
\hline Hospitalization duration & 1.530 & 129.016 & .000 & 1 & .991 & 4.617 \\
\hline Tube duration & -23.583 & 1374.304 & .000 & 1 & .986 & .000 \\
\hline BMI & 3.073 & 699.781 & .000 & 1 & .996 & 21.602 \\
\hline WBC & -1.357 & 219.637 & .000 & 1 & .995 & .257 \\
\hline HCT & -6.166 & 469.569 & .000 & 1 & .990 & .002 \\
\hline PLT & -.100 & 10.959 & .000 & 1 & .993 & .905 \\
\hline CRP & -.213 & 24.202 & .000 & 1 & .993 & .808 \\
\hline INR & 104.632 & 9309.472 & .000 & 1 & .991 & $2.761 \mathrm{E}+045$ \\
\hline D.Dimer & .006 & 1.141 & .000 & 1 & .996 & 1.006 \\
\hline $\mathrm{CT}(1)$ & -61.000 & 5065.426 & .000 & 1 & .990 & .000 \\
\hline Constant & 53.130 & 32811.905 & .000 & 1 & .999 & 118599512555920720000000.000 \\
\hline
\end{tabular}

ICU: Intensive care unit, BMI: body mass index, WBC: white blood cell, HCT: hematocrit, PLT: platelet, CRP: C reactive protein, INR: International normalized ratio, CT:

Computed tomography 
Ghoniem et al. (4) which was a HEPA filter on the tip of the UWSB and dilute household bleach (5.25-6.15\% sodium hypochlorite) with a ratio of $1: 50$ to the fluid in the water seal.

Although new measures have been recommended for interventions with patients undergoing TT, there has to date been no study showing the clinical significance of these recommendations in literature. Accordingly, the present study is the first clinical research assessing the tube thoracostomy technique applied with transmission prevent recommendations.

In our patient series, $81.10 \%$ were male. Previous studies examining the COVID-19 and PNX relationship also found the number of male patients to be higher than women $(9,14,15)$. Furthermore, previous studies evaluating the factors affecting mortality in COVID-19 patients have established a higher rate of mortality in male patients than in female patients. For instance, Williamson et al. (16) reported the male gender and the presence of cardiovascular disease, diabetes and respiratory disease among the comorbidities to be associated with mortality. Zhou et al. (17) found that $70 \%$ of the non-surviving patients were male, and identified hypertension and diabetes mellitus as comorbidities affecting mortality. Harrison et al. (18), in turn, reported that $59 \%$ of the patients in their study who died were male, and that mortality was increased by the presence of comorbidities such as kidney failure, diabetes mellitus and heart failure. These studies have shown that presence of comorbid diseases such as hypertension, diabetes, renal failure and heart failure is associated with mortality. We classified the comorbidities of our patients as pulmonary and non-pulmonary, but could not identify any association between the pulmonary/non-pulmonary nature of comorbidities and mortality, although the presence of comorbidities was found to be associated with mortality. Considering the COVID-19 positivity of all the patients in this present series, our findings were consistent with these studies evaluating mortality in COVID-19.

The patients in the present study were younger than those reported on in previous studies investigating the relationship between COVID-19 and PNX $(9,14,15)$. When the evaluation was performed in terms of age, the mortality was found to be increased by increasing age of the patients. Similar to this present study, Willimson et al. (16), and Zhou et al. (17), in their study evaluating the factors affecting the mortality in COVID-19 patients, reported that old-age increased mortality. The mortality is increased in patients with old-age due to the impaired immune system and decelerated healing due to inefficient cytokine response secondary to old-age (19). Therefore, we think that the COVID-19 disease is more deadly in elderly patients.
An examination of the CRP, INR and D-dimer laboratory values examined in the present study were found to be associated with mortality. Previous studies have reported inflammatory markers (CRP) to be associated with COVID-19 severity, and COVID-19 infection has been reported to increase the likelihood of thrombosis development, and to increase $\mathrm{D}$-dimer levels, one of the fibrin degradation products (20). Liao et al. (21) and Wu et al. (22) reported D-dimer, coagulation markers and inflammatory markers to be associated with mortality in COVID-19 patients, although according to these studies, and concurring with our findings, the specificity of laboratory markers in predicting prognosis in COVID-19 patients is limited, needing to be assessed together with the patient's clinical picture.

When the tube techniques were compared; the number of days of tube duration was lower in the patients administered the preventive procedure (group 2) than in those administered the traditional procedure (group2). We suggest that the result we achieved is important since the criteria for discontinuation of the tube were same in both groups. As an explanation for this, while there was limited information on the course of COVID-19 in the early days of the pandemic. We have seen that we can more efficiently treat COVID-19 with increasing knowledge on the disease and new recommendations for treatment have been published. PNX was found to be regressed rapidly due to the effective treatment of the SARS-CoV-2 infection in the lungs in patients who were treated after June 2020. Also, tube duration time was found to be shorter in these patients due to the sufficient expansion of the lungs. In addition, we suggest that healing was more rapid in these patients since the viral load was lowered due to the prevention of viral contamination of the room air by placement of an hypochlorite acid added filter to the exit hole of the USWB. HEPA filters are known to capture particles that are $0.3 \mu \mathrm{m}$ in size. The size of droplets is $0.5 \mu \mathrm{m}$. Although the size of SARS-CoV-2 virus is $0.07-0.09 \mu \mathrm{m}$, it will be trained by the HEPA filter as it is transmitted via droplets (23). When draining air from the pleural cavity of patients, the SARS-CoV-2 virus would pass up the thoracostomy tube to the UWSD bottle, and from there into the ambient air.We consider that the spread was prevented by placement of a filter to the exit hole of the UWSD and adding hypochlorite acid into the bottle. The study by Duffy et al. (24) supports this thesis Duffy et al. (24) used an experimental set-up in their analysis of the two modes of administration to measure the particle count in the air in the UWSD bottle through air-leak in the laboratory setting, and recorded a significantly reduced particle emission count when the HEPA filter was installed on the outlet when compared to a set-up without a filter. 
When the two tube application techniques were compared, no difference was noted in intensive care unit admissions, the duration of hospital stay and mortality of the patients group 1 and group 2 . It can be interpreted from these findings that the transmission preventive recommendations do not have adverse effect on the treatment or prognosis of the patients.

This study has some limitations. The most significant limitation of our study is its retrospective and singlecenter design and the limited number of patients. Tube thoracostomy procedures were performed in the emergency service and the patients were hospitalized to the appropriate wards and intensive care units. It cannot be determined whether any contamination occurred from these patients to the healthcare service providers since the healthcare providers contacting these patients were also involved in the treatment and follow-up processes of other patients as well.

\section{CONCLUSION}

In conclusion, tube thoracostomy is an interventional procedure with a high risk of contamination for droplet transmitted diseases such as COVID-19 that involve the respiratory tract. It has been suggested to put hypochlorite acid in the tube thoracostomy bottle and a filter in the outlet hole in order to prevent infection of the healthcare workers who perform this procedure. This is a cheap, simple and easily available protocol. In this study, we evaluated the effect of this procedure on patients. According to the results we obtained, we found that the new recommendations do not have an adverse effect on the patient. In light of the experience we gained from the SARS-CoV-2 pandemics, we consider that transmission preventing protocols should be continued even after the pandemic is over. Large scale multicenter studies are required in order to develop and standardized new protocols.

\section{ETHICAL DECLARATIONS}

Ethics Committee Approval: It was approval by the Turkish Ministry of Health, dated January 02, 2021 and numbered T21-31-12, and by the İzmir Katip Çelebi University Ethics Committee dated January 21, 2021 and numbered 003.

Informed Consent: All patients signed the free and informed consent form.

Referee Evaluation Process: Externally peer-reviewed.

Conflict of Interest Statement: The authors have no conflicts of interest to declare.

Financial Disclosure: The authors declared that this study has received no financial support.
Author Contributions: The authors declare that they have all participated in the design, execution, and analysis of the paper, and that they have approved the final version.

\section{REFERENCES}

1. Sahn SA, Heffner JE. Spontaneous Pneumothorax. New Engl J Med 2000; 342: 868-74

2. Bilkhu R, Viviano A, Saftic I, Billè A. COVID-19: Chest Drains With Air Leak - The Silent 'Super Spreader'? 2020. doi:10.25373/ ctsnet. 12089130

3. Pieracci FM, Burlew CC, Spain D, et al. Tube thoracostomy during the COVID-19 pandemic: guidance and recommendations from the AAST Acute Care Surgery and Critical Care Committees. Trauma Surg Acute Care Open 2020; 5: ne000498.

4. Ghoniem A, Abdellateef A, Osman AI, Elsayed HH, Elkhayat H, Adel W. A tentative guide for thoracic surgeons during COVID-19 pandemic. Cardiothorac Surg 2020; 28: 16.

5. Yang X, Yu Y, Xu J, et al. Clinical course and outcomes of critically ill patients with SARS-CoV-2 pneumonia in Wuhan, China: a single-centered, retrospective, observational study.Lancet Respir Med 2020; 8: 475-81

6. Chen N, Zhou M, Dong X, et al. Epidemiological and clinical characteristics of 99 cases of 2019 novel coronavirus pneumonia in Wuhan, China: a descriptive study. Lancet 2020; 395: 507-13.

7. Aiolfi A, Biraghi T, Montisci A, et al. Management of persistent pneumothorax with thoracoscopy and bleb resection in COVID-19 patients. Ann Thorac Surg 2020; 110: 413-5.

8. Hallifax R, Wrightson J, Bibby, Walker S, Stanton A, Fonseka DD. Pleural services during the COVID-19 pandemic (V2.0). British Thoracic Society, 2020.

9. Ceylan KC, Batihan G, Yazgan S, Gürsoy S, Kıraklı SC, Ataman S. Pleural complications in patients with coronavirus disease 2019 (COVID-19): how to safely apply and follow-up with a chest tube during the pandemic? Eur J Cardiothorac Surg 2020; 58: 1216-21.

10. Wei PF. Diagnosis and treatment protocol for novel coronavirus pneumonia (Trial Version 7). Chin Med J (Engl) 2020; 133: 1087-95.

11.Simpson S, Kay FU, Abbara S, et al. Radiological Society of North America Expert Consensus Statement on Reporting Chest CT Findings Related to COVID-19. Endorsed by the Society of Thoracic Radiology, the American College of Radiology, and RSNA. Radiology: Cardiothoracic Imaging 2020; 2: e200152.

12. Gedik IE, Timuçin Alar T. Protective measures undertaken during chest tube thoracostomy in COVID-19 outbreak. Indian J Thorac Cardiovasc Surg 2021; 37: 211-4.

13. Irons JF, Pavey W, Bennetts JS, Emily G, Elli T, Aubrey A. COVID-19 safety: aerosol-generating procedures and cardiothoracic surgery and anesthesia - Australian and New Zealand consensus statement. Med J Aust 2021; 214: 40-4.

14. Miró O, Llorens P, Jiménez S, et al. Frequency, risk factors, clinical characteristics, and outcomes of spontaneous pneumothorax in patients with coronavirus disease 2019: a case-control, emergency medicine-based multicenter study. Chest 2021; 159: 1241-5.

15. Martinelli AW, Ingle T, Newman J, et al. COVID-19 and pneumothorax: a multicentre retrospective case series. Eur Respir J 2020; 56: 2002697.

16. Williamson EJ, Walker AJ, Bhaskaran K, et al. Factors associated with COVID-19-related death using Open SAFELY. Nature 2020; 584: 430-6.

17.Zhou F, Yu T, Du R, et al. Clinical course and risk factors for mortality of adult inpatients with COVID-19 in Wuhan, China: a retrospective cohort study. Lancet 2020; 395: 1054-62. 
18. Harrison SL, Eynullayeva EF, Lane DA, Underhill P, Lip GYH. Comorbidities associated with mortality in 31,461 adults with COVID-19 in the United States: A federated electronic medical record analysis. PLoS Med 2020; 17: e1003321.

19. Opal SM, Girard TD, Ely EW. The immunopathogenesis of sepsis in elderly patients. Clin Infect Dis2005; 41: 504-12.

20. Aggarwal S, Telles NG, Aggarwal G, Lavie C, Lippi G, Henry BM. Clinical features, laboratory characteristics, and outcomes of patients hospitalized with coronavirus disease 2019 (COVID-19): Early report from the United States. Diagnosis (Berl) 2020; 7: 916.

21. Liao D, Zhou F, Luo L, et al. Haematological characteristics and risk factors in the classification and prognosis evaluation of COVID-19: a retrospective cohort study. Lancet Haematol 2020; 7: e671-e8.

22. Wu C, Chen X, Cai Y, et al. Risk factors associated with acute respiratory distress syndrome and death in patients with coronavirus disease 2019 pneumonia in Wuhan, China. JAMA Intern Med 2020; 180: 934-43.

23. Carvalho EA, Oliveira MVB. Safety model for chest drainage in pandemic by COVID-19. Rev Col Bras Cir 2020; 47: e20202568.

24. Duffy C, Kidd A, Francis S et al. BMJ Open Respir Res 2020; 7: e000710. 